him what he had done and he said that he had tried all the patent foods and that they were "no good" (most of us can remember the time when everybody's patent food "cured" infantile diarrhoea-according to the proprietors). suggested the efficacy of "boiling the milk" and every feed of milk. He retorted that he was told in hospital that boiled milk caused scurvy rickets, \&c. I asked him if he had ever seen a case from boiled milk and he said "Well, not that he could really rely on." My reply was, "Well, you have seen seven deaths from 'unboiled' milk." He was also astonished to hear that during my 15 years' close observation of the feeding of infants in private and hospital practice I had not seen one single case due to boiled milk; verb. sap. So long as we have two schools of thought -the boiled-milk-scurvy-rickets school and the other-side school-so long shall we have a heavy infantile death-rate from diarrhoea. In my book "Intestinal Intoxication in Infants" 1 I dealt fully with every problem commonly arising in the etiology, prevention, pathology, and treatment of infantile diarrhoea, and the materials were gleaned from a prolonged experience of private and hospital practice and many of the facts stated were the result of original research carried out during the greater part of my medical career. This emboldens me to join in this discussion and to make a suggestion which I have been putting into practice lately with success.

The putrescibility of milk-ordinary cow's milk-is the factor to be dealt with. Why not get rid of this by removing the "water" from the milk, and by using a good, sweet, natural, soluble, and palatable milk powder put an end to the summer-heat and ignorant-person difficulty? During June, July, August, and September, when the earth thermometer reaches a well-known elevation, is the time when milk is most lethal to infants. Why not feed the children of the poor and ignorant, who cannot carry out sterilising directions efficiently, on dried milk powder? Indeed, why not feed all children on dried milk during the heat of summer and at other times if necessary or desirable? Dried vaccine, antidiphtheritic serum, and antivenene can be preserved dry and yet be efficient. Why not do the same with milk? Hitherto it has been impossible to obtain a soluble, non-cheesy, non-mawkish, cheap milk powder.

Messrs. Freud and Co., of 19, St. Dunstan's-hill, London, E.C., have provided me with a soluble, fresh, palatable, and cheap natural milk powder which I have used with much success, and they will, I am sure, send samples of the same to those of your readers desiring it. This milk powder has the following advantages : (1) it is cheap; (2) it can be prepared as a food very quickly ; (3) it can be kept and transported to places where milk is difficult to obtain ; (4) it will keep sweet and fresh for long periods of time; (5) pure milk can be made from it at all times ; (6) it ensures the infant getting a "warm feed" and a non-poisonous one; (7) no more need be liquefied than is needed for a feed ; (8) it is as nutritious and safe as boiled fresh milk and less dangerous than the average milk in most houses ; (9) it cannot if kept dry be easily contaminated; (10) it can be used in any proportion as regards its albumin, fat, sugar, and salts ; (11) it can be used to prepare "humanised milk"; (12) it is prepared from fresh, sterilised, natural milk without precipitation and by the instantaneous evaporation of its water only, \&c. ; (13) I have not yet come upon any sound objection to its use ; (14) it is better than many samples of ordinary milk, for it is safe bacteriologically; and (15) it can be used turn about with good new milk, if new milk is scarce or is unobtainable, as during a hot night in summer. I trust that the above suggestions will provide material not for controversial purposes but to afford some means of combating what is, indeed, the most deadly scourge of infantile life.

I am, Sirs, yours faithfully,

F. W. Forbes Ross, M.D. Edin., F.R C.S. Eng., Gower-street, W.C. D.P.H. Lond., \&c.

\section{A VERY SIMPLE CONTRIVANCE TO AID MYOPIC AND OTHER FAILING EYES, ESPECIALLY IN READING.}

\section{To the Editors of THE LANCET.}

SIRs,-As with failing eyesight I have received, especially in reading, for some years very considerable assistance from a very simple contrivance it may help some of your readers over a difficulty if I state very briefly and in quite simple terms what $I$ have in view without subjecting it to any discussion on grounds of priority, as no doubt, it has occurred to many people before. My eyes have been very myopic all along and have required very strong concave lenses which, however, modified by the process of aging, kept me very comfortable and in a certain sense as well off as the average man up to about ten years ago when a separation of the retina occurred in the left eye which entirely destroyed it for practical purposes and left me dependent for vision on the other eye in which I found there was a commencing, but happily not a perceptibly advancing, cataract. 'The problem therefore now is how to use the remains of power in this right eye so as to persevere as much as possible with my reading which, owing to my other infirmities, is more and more important for me as an occupation. Ever since the commencement of old age I have found that reading is best done without any lens and at a distance of four or five inches from the page. It is by economising and aiding this limited visual power that I find the contrivance above referred to is of the greatest use. It consists simply of a conical tube of light pasteboard material so prepared as to have diameters at the side applied to the eye of two and a quarter by one and a quarter inches, while the diameters of the opposite end of the cone (the one nearest the book) measure one and a half by one inches, the length of the cone being approximately two and a half inches. The machine is held in place by a simple bit of elastic and is so cut as to be adapted to the eye of the side on which it is applied and blackened within by some opaque application shutting off all accidental or useless rays. To prevent undue friction the edge next the face is guarded by a little velveteen and so the job is at once complete and anyone can either make it for himself or get it made at any stationer's. Were there any demand for such articles they might easily be turned out at a cost of a few pence. The service done is entirely by shutting off side rays and limiting the vision in area with corresponding distinctness in detail. I can most truly say that for the last year or two this little invention has enabled me to continue a reader even of very moderatesized print under the difficulties above referred to.

Sept. 24th, 1904 I am, Sirs, yours faithfully,

\section{THE HYGIENE OF THE BARBER.}

\section{To the Editors of THE LANCET.}

SIRS,-In connexion with your article upon this subject in THE LANCET of Sept. 24th, p. 902, I should like to be allowed to point out that although the regulations which you suggest if strictly enforced would reduce to a minimum the risks which are now to be met with in a hairdresser's shop, there are still two other ways in which partial safety is to be found, at any rate in so far as hair-cutting is concerned. One way is by the establishment of visiting hairdressers who would use the personal brushes and combs of those they operated upon. I know of at least one hairdresser who gave up his shop and arranged with his customers to call upon them periodically at fixed dates. His charges were not raised, for he frequently attended upon several members of the same family at one visit and I believe he managed to make a fair income. Another way is to carry out a practice which is even now adopted to a limited extent, and that is to take one's own brush and comb when paying a visit to the hairdresser.

Sept. 27th, 1904 I am, Sirs, yours faithfully, HERBERT JONES。

\section{THE HOLMAN TESTIMONIAL FUND. To the Editors of THE LANCET.}

Sirs, - At a meeting of the committee held this afternoon it was decided to close the fund in a fortnight from the present date. In the meantime I may so far anticipate the final report as to state that the amount received will leave a net balance of a little over $\$ 400$ to be expended on the object to which it was decided that the fund should be devoted, the erection of a room in connexion with Epsom College which will be a reading-room for the boys out of school hours and will also serve as a studio in which drawing may be taught while they are in school.

The original estimate was $£ 500$ and while $£ 400$ can be made to serve the purpose it is greatly to be desired that the comfort and convenience and appearance of the room should 